\title{
RETRACTED ARTICLE: Transcriptional retargeting of herpes simplex virus for cell-specific replication to control cancer
}

\author{
Weihua Lou ${ }^{1,2} \cdot$ Fang $\mathrm{Ji}^{1,2} \cdot$ Jianing $\mathrm{Fu}^{3} \cdot$ Zhiqiang $\mathrm{Han}^{4} \cdot$ Wen $\mathrm{Di}^{1,2,3,4} \cdot$ Ning Zhang ${ }^{1,2} \mathbb{C}$
}

Received: 13 December 2017 / Accepted: 18 December 2017 / Published online: 5 January 2018

c) Springer-Verlag GmbH Germany, part of Springer Nature 2018

The Editor-in-Chief is retracting this article [1] because of overlap with other published articles, most significantly with [2-4]. Jianing Fu and Ning Zhang agree with this retraction. Weihua Lou, Fang Ji, Zhiqiang Han and Wen Di have not responded to correspondence about this retraction.

1. Lou W, Ji F, Fu J, Han Z, Di W, Zhang N. Transcriptional retargeting of herpes simplex virus for cell-specific replication to control cancer. J Cancer Res Clin Oncol (2018). https://doi.org/10.1007/s00432-017-2566-4

2. Mullen JT, Kasuya H, Yoon SS, Carroll NM, Pawlik TM, Chandrasekhar S, Nakamura H, Donahue JM, Tanabe KK. Regulation of herpes simplex virus 1 replication using tumor-associated promoters. Ann Surg. 2002;236:502-512
3. Kasuya H, Pawlik TM, Mullen JT, Donahue JM, Nakamura H, Chandrasekhar S, et al. Selectivity of an oncolytic herpes simplex virus for cells expressing the DF3/MUC1 antigen. Cancer Res. 2004;64:2561-7

4. Yamamura H, Hashio M, Noguchi M, Sugenoya Y, Osakada M, Hirano N, Sasaki Y, Yoden T, Awata N, Araki N, Tatsuta M, Miyatake SI, Takahashi K. Identification of the transcriptional regulatory sequences of human calponin promoter and their use in targeting a conditionally replicating herpes vector to malignant human soft tissue and bone tumors. Cancer Res. 2001;61:3969-77
Electronic supplementary material The online version of this article (https://doi.org/10.1007/s00432-017-2566-4) contains supplementary material, which is available to authorized users.

\section{Wen Di}

diwen163@163.com

Ning Zhang

ningning1723@126.com

1 Department of Obstetrics and Gynecology, Ren Ji Hospital, School of Medicine, Shanghai Jiao Tong University, Shanghai 200126, China

2 Shanghai Key Laboratory of Gynecologic Oncology, Shanghai 200126, China

3 Columbia Center for Translational Immunology, Columbia University Medical Center, New York, NY 10032, USA

4 Viri Biotechnology Company Limited, No. 8 Guohuai Street, Zhengzhou, Henan 450052, China 